\title{
Original
}

\section{Cytokine response to diabetic ketoacidosis (DKA) in children with type 1 diabetes (T1DM)}

\author{
Kyriaki Karavanaki $^{1)}$, Evangelia Karanika ${ }^{1)}$, Soultana Georga ${ }^{1)}$, Anastasia Bartzeliotou ${ }^{2)}$, \\ Manolis Tsouvalas $^{1)}$, Ilias Konstantopoulos ${ }^{1)}$, Aspasia Fotinou ${ }^{3)}$, Ioannis Papassotiriou ${ }^{2)}$ and \\ Christina Karayianni ${ }^{1)}$ \\ ${ }^{1)}$ Diabetic Clinic, B'Paediatric Department, University of Athens Medical School,“P.\&A.Kyriakou” Children’ s Hospital, Athens, Greece \\ ${ }^{2)}$ Department of Clinical Biochemistry, “Aghia Sophia” Children’s Hospital, Athens, Greece \\ ${ }^{3)}$ Hormones Laboratory, "P. \& A. Kyriakou” Children's Hospital, Athens, Greece
}

\begin{abstract}
It has been suggested that cytokine release during DKA may result in capillary perturbation and thus may contribute to the development of its acute clinical complications (i.e.cerebral or pulmonary edema). We studied in 38 newly diagnosed T1DM children with DKA, aged 7.68 \pm 3.07 years, plasma levels of cytokines IL-1 $\beta$ (interleukin-1 $\beta$ ), IL-2, IL-6, IL-8, IL-10, TNF- $\alpha$ (tumour necrosis factor- $\alpha$ ) and also WBC (white blood cell count), hs-CRP (high sensitivity C-reactive protein), GH (growth hormone) and cortisol, prior to, during and $120 \mathrm{~h}$ after DKA management, with the aim to monitor their levels at different time-points and in different degrees of DKA severity. Prior to DKA management the levels of IL-6, IL-8, IL-10, WBC and cortisol were elevated, but were all reduced within 120h after DKA management. Then the patients were divided into two groups: a. moderate/severe: $\mathrm{pH} \leq 7.2$, b. mild DKA: $\mathrm{pH}>7$.2. In the group with moderate/severe DKA (ph $\leq 7.2)$, IL-10 levels were the highest of all cytokines, but were significantly decreased after $6 \mathrm{~h}(91.76 \mathrm{vs} 18.04 \mathrm{pg} / \mathrm{mL}$, $p=0.008)$, with no further change, while IL-6 levels were decreased at $120 \mathrm{~h}(28.32 \mathrm{vs} 11.9 \mathrm{pg} / \mathrm{mL}, p=0.003)$. The above were not observed in the group with mild DKA. In conclusion, in the children with DKA of our study, in the group with moderate/severe DKA the IL-10 levels were prematurely reduced at 6 hours, while the IL-6 levels remained high and were reduced at 120 hours after the DKA management. These changes may be responsible for increased capillary perturbation, which could lead to the subsequent development of acute DKA complications.
\end{abstract}

Key words: Type 1 diabetes mellitus, Ketoacidosis, Cellular activation, Cytokines

DIABETES MELLITUS (DM) is a chronic metabolic disorder caused by an absolute or relative deficiency of insulin. Diabetic ketoacidosis (DKA) is an acute potentially life-threatening complication of diabetes, which remains the leading cause of hospitalization, morbidity and death in children with type 1 diabetes (T1DM) [1].

Subclinical brain edema [2,3] and interstitial pulmonary edema [4] have been reported to be present in children and adolescents with DKA prior to treatment initiation. The factors that are possibly associated with their aetiopathogenesis are higher serum urea nitrogen concentrations, lower pressures of arterial carbon dioxide at the time of diagnosis of DKA, as well as bicarbo-

Submitted May 13, 2011; Accepted Aug. 25, 2011 as EJ11-0024 Released online in J-STAGE as advance publication Oct. 28, 2011

Correspondence to: Kyriaki Karavanaki, M.D., Ph.D., Paediatrics and Paediatric Diabetes, Second University Department of Paediatrics, "P. \& A. Kyriakou" Children's Hospital, Goudi 11527, Athens, Greece. E-mail: kkarav@yahoo.gr nate treatment [5]. Moreover it has been suggested that cytokine release during DKA may be responsible for the above acute clinical complications of DKA in children with T1DM [6]. The pathophysiology of these complications remains uncertain, but it is likely that they involve some degree of capillary perturbation that begins prior to the management of DKA and is accentuated by its treatment [6].

Interleukins are a wide spectrum of small regulatory protein molecules encompassed in the family of cytokines [7]. Among the numerous physiologic responses that require cytokine involvement are development of cellular and humoral immune responses, induction of the

Abbreviations: IL, Interleukins; TNF- $\alpha$, Tumour necrosis factor- $\alpha$; IFN, Interferon- $\gamma$; BMI, Body mass index; WBC, White blood cell count; ANC, Absolute neutrophil count; hs-CRP, High sensitivity C-reactive protein; $\mathrm{PCO}_{2}$, Partial Pressure of $\mathrm{CO}_{2} ; \mathrm{GH}$, Growth hormone; BUN, Blood urea nitrogen; Osm, Osmolality; AntiGAD, Glutamic acid decarboxylase antibodies; IA-2=Insulinoma antigen-2 antibodies 
inflammatory response, regulation of haematopoiesis, control of cellular proliferation and differentiation [8].

Chemokines play a central role in inflammatory processes by regulating leukocyte migration into sites of tissue damage [9]. IL-6 is secreted by macrophages, lymphocytes and other cells [10]. It has been previously reported that hyperglycaemia increases serum concentrations of IL-6 $[11,12]$ possibly through augmented production in monocytes $[11,13]$. Thus patients with diabetes have elevated blood levels of IL-6, which, together with TNF- $\alpha$ are known to increase inflammation and the development of vascular disease and atherosclerosis, possibly by increasing oxidative stress $[12,14,15$, 16]. In children with T1DM, IL-6 levels were found to be statistically significantly increased in the group with long T1DM duration, as well as in those newly diagnosed, when compared with healthy controls $[6,9]$, with the highest levels in the newly diagnosed patients [9].

The effect of IL- 6 on the blood-brain barrier (BBB) failure has been previously studied in patients with brain tumours under chemotherapy [17]. Thus it has been shown that IL- 6 triggers production of metalloproteinase inhibitors, such as alpha 2-macroglobulin by perivascular astrocytes [17], resulting in BBB failure and perivascular cerebral edema. Also elevated circulating levels of IL- 6 have been reported to enhance pulmonary permeability and endothelial damage in different conditions, such as ischemia-perfusion during lung transplantation [18], pulmonary exposure to diesel [19], or intestinal ischemia [20]. Moreover other proinflammatory cytokines, such as TNF- $\alpha$, IL- $1 \beta$ and IFN- $\gamma$ (Interferon- $\gamma$ ) have been shown to increase pulmonary permeability, resulting in pulmonary edema [21].

IL-10 is secreted by activated monocytes/macrophages and lymphocytes. IL-10 has been reported to have multifaceted anti-inflammatory properties and to play a beneficial regulatory role in atherogenesis [22]. Also IL-10 levels have been found to increase during DKA and its management [6]. The role of IL-10 in reducing microvascular leakage has been shown in many previous studies. Thus it has been shown [23, 24] that IL-10 is a powerful inhibitor of the secretion of vascular permeability factor (VPF) of peripheral blood mononuclear cells, and that this occurs in a dose-dependent fashion [25]. Moreover, in rats with acute lung injury the treatment with endothelial progenitor cells resulted in a dramatical increase of IL-10 levels and the reduction of pulmonary edema [26].

Thus previous studies support that pro-inflamma- tory cytokines, and especially IL-6, play a central role in inflammation increase and endothelial damage, while anti-inflammatory IL-10 has a protective role by decreasing vascular wall permeability. Although there are some previous studies on the role of cytokines in the development of long-term diabetes complications $[6,9$, $12,14,15,16]$, there is only one study on the fluctuation of cytokines during the metabolic crisis of DKA in children with T1DM [6], including limited number of patients. The aim of the present study was to monitor serum levels of pro-inflammatory cytokines IL-1 $\beta$, IL-2, IL-6, IL-8 and TNF- $\alpha$ and the anti-inflammatory cytokine IL-10 at different time-points during the management of DKA, as markers of the risk of development of its acute complications. Another aim was to study the fluctuation of interleukin levels in patients with different degrees of severity of DKA.

\section{Patients and Methods}

\section{Patients}

The study included 38 newly diagnosed children with T1DM and DKA (14 boys and 24 girls), which were admitted in a University Paediatric Department during the period of two years. The criteria for the diagnosis of T1DM were fasting plasma glucose levels of $126 \mathrm{mg} / \mathrm{dL}(7.0 \mathrm{mmol} / \mathrm{L})$, or symptoms of hyperglycaemia (polyuria, polydipsia, and unexplained weight loss with a random plasma glucose $\geq 200 \mathrm{mg} / \mathrm{dL}$ (11.1 $\mathrm{mmol} / \mathrm{L}$ ) [27]. DKA was defined as hyperglycaemia with blood glucose levels exceeding $11 \mathrm{mmol} / \mathrm{L}$, heavy glycosuria $(>55 \mathrm{mmol} / \mathrm{L})$, ketonuria and metabolic acidosis $(\mathrm{pH}<7.30)$ with a bicarbonate level of $<15$ $\mathrm{mmol} / \mathrm{L}$ and the presence of $>5 \%$ dehydration [28].

The patients had no evidence of acute pancreatitis or acute/ chronic infection according to history and physical examination. Although some presented with leucocytosis, it subsequently subsided without the administration of antibiotics.

\section{Methods}

Blood samples were drawn: a. a baseline sample at presentation, before initial hydration, b. at 6 hours, c. at 24 hours and $d$. at 120 hours after administration of fluids and insulin. Laboratory tests included samples for cytokine levels, blood $\mathrm{pH}$ and glucose levels, serum electrolytes, blood urea nitrogen (BUN), osmolality (Osm), WBC, absolute neutrophil count (ANC), hsCRP levels, blood and urine cultures. We also deter- 
mined serum GH and cortisol levels at presentation and after 120 hours.

We determined serum levels of cytokines IL-1 $\beta$, IL-2, IL-6, IL-8 IL-10 and TNF- $\alpha$, using the Luminex XMAP technique. All samples were drawn in citrated tubes and then they were immediately centrifuged at $4^{\circ} \mathrm{C}$ and 3500rpm for 6 minutes. Values $\leq 5 \mathrm{ng} / \mathrm{L}$ were considered as normal.

Serum cortisol levels were estimated using the Electrochemiluminescence technique (Cortisol Elecsys 2010, Roche Diagnostics) and GH levels were estimated using the Chemiluminescence technique (Ultrasensitive hGH Access Beckman-Coulter). The calibrators of the method are based on the 2nd International Standard WHO 98/574. The transformation factor of $\mu \mathrm{IU} / \mathrm{mL}$ into $\mathrm{ng} / \mathrm{mL}$ was $1 / 3$.

Treatment of diabetic ketoacidosis (DKA) was performed in the Paediatric Department under the care of the same Paediatric Diabetologist, according to the protocol [29]. Informed consent was obtained from the parents.

\section{Statistical analysis}

Descriptive statistics were calculated for demographic characteristics of patients with DKA and T1DM at presentation and before treatment initiation.

Repeated measures ANOVA models were applied in order to determine the differences in cytokines, WBC, ANC and plasma cortisol levels between different time-points: i.e. pre-treatment and at $6-8 \mathrm{~h}, 24 \mathrm{~h}$ and $120 \mathrm{~h}$ after treatment initiation, taking into account the degree of severity of DKA. Results are summarized in terms of the estimated marginal means and corresponding 95\% C.I.'s. Comparison of cytokine levels between two time-points was performed with the Wilcoxon's rank sum test for two samples. Spearman rank correlation coefficients were used to investigate the relationship of the cytokine levels with the $\mathrm{pH}$ levels and also the correlation of the change in IL-10 levels (0-6h) with serum osmolality. Two tailed $p$-values $<0.05$ were considered significant. The statistical analysis was performed using the SPSS 17 statistical package.

\section{Results}

The patients with newly diagnosed T1DM of our study had a mean age of $7.68 \pm 3.07$ years (range: $2-13$ years), and among them 14 were boys and 24 girls. The clinical and laboratory characteristics of the patients according to the severity of DKA at presentation and before treatment initiation are shown in Table 1. The mean $\mathrm{pH}$ at presentation was $7.14 \pm 0.12$, while severe DKA $(\mathrm{pH} \leq 7.0)$ had 6 patients, moderate ( $\mathrm{pH}: 7.01-7.20)$ had 16 patients and mild $(\mathrm{pH}>7.20)$ had 16 patients. In the moderate/severe DKA group, $4 / 22$ patients were in poor condition and none was in coma (Table 1). When comparing the two groups according to DKA severity, patients with moderate/severe DKA had higher WBC and lower C-peptide, $\mathrm{HCO}_{3}$ and $\mathrm{PCO}_{2}$ levels than those with mild DKA, while 21/22 of them were glutamic acid decarboxylase antibodies (anti-GAD) positive and 18/22 were insulinoma antigen- 2 antibodies (IA-2) positive (Table 1).

Results from the Repeated measures ANOVA models are summarized in Table 2. Overall, the WBC, ANC and IL-10 levels presented significant changes over time. More specifically, WBC and ANC levels were significantly lower in blood samples drawn $24 \mathrm{~h}$ after administration of fluids and insulin than in the initial (baseline) blood samples. The WBC and ANC levels were further decreased at $120 \mathrm{~h}$ following the DKA management initiation. In the total group of patients the IL-10 levels were significantly higher in the initial blood sample compared with all subsequent blood samples. Moreover the IL-10 levels were significantly decreased at 6-8h after DKA management initiation, while no significant changes were observed $24 \mathrm{~h}$ and $120 \mathrm{~h}$ later.

The effect of time on the WBC, ANC and IL-10 levels is different according to the degree of severity of DKA (Table 2 - columns 1-3). More specifically, the leucocytosis and the significant decrease in WBC levels mainly regard children with moderate or severe DKA. Moreover, the high levels of IL-10 in the initial blood sample and their significant decrease at 6-8 hours after treatment initiation (91.76 vs $18.04 \mathrm{pg} / \mathrm{mL}, p=0.008$ ) and at all subsequent time-points concern the subgroup of children with moderate or severe DKA. On the contrary, in the group with mild DKA the initial IL-10 levels were low and were not significantly changed over time (see Fig. 1).

Regarding the remaining cytokines and plasma levels of GH and cortisol no significant changes were observed, neither with time nor with the degree of severity of DKA (Table 2). However the absence of statistical significance, using the Repeated measures ANOVA models does not preclude the clinical importance of some of those results. More specifically, we focus on the IL-6 levels in the group with moderate or severe DKA, which were initially elevated and were 
Table 1 Demographic characteristics of patients with different degrees of severity of DKA

\begin{tabular}{lccc}
\hline & $\begin{array}{c}\text { Mild DKA } \\
(\mathrm{N}=16)\end{array}$ & $\begin{array}{c}\text { Moderate/severe DKA } \\
(\mathrm{N}=22)\end{array}$ & $p$ \\
\hline Age $($ years $)$ & $8.59 \pm 2.70$ & $6.44 \pm 3.25$ & 0.135 \\
Gender $($ boys $\%)$ & $4 / 16(25 \%)$ & $10 / 22(45.45 \%)$ & 0.633 \\
$\mathrm{BMI}\left(\mathrm{kg} / \mathrm{m}^{2}\right)$ & $16.11 \pm 1.83$ & $16.09 \pm 2.18$ & 0.987 \\
$\mathrm{WBC}\left(\mathrm{x} 10^{3} / \mu \mathrm{L}\right)$ & $9.8 \pm 3.0$ & $18.3 \pm 6.6$ & 0.003 \\
$\mathrm{CRP}(\mathrm{mg} / \mathrm{L})$ & $1.00 \pm 1.07$ & $12.00 \pm 21.42$ & 0.168 \\
$\mathrm{Glucose}(\mathrm{mg} / \mathrm{L})$ & $462.75 \pm 165.09$ & $469.82 \pm 121.71$ & 0.915 \\
$\mathrm{HCO}_{3}(\mathrm{mmol} / \mathrm{L})$ & $10.50 \pm 3.16$ & $5.36 \pm 2.29$ & 0.001 \\
$\mathrm{PCO}_{2}(\mathrm{mmHg})$ & $25.75 \pm 7.81$ & $19.24 \pm 5.50$ & 0.048 \\
$\mathrm{BUN}(\mathrm{mg} / \mathrm{L})$ & $24.38 \pm 9.34$ & $29.45 \pm 16.47$ & 0.445 \\
Osm $(\mathrm{mosm} / \mathrm{L})$ & $299.09 \pm 12.01$ & $300.13 \pm 5.74$ & 0.825 \\
$\mathrm{pH}(0 \mathrm{~h})$ & $7.25 \pm 0.03$ & $7.06 \pm 0.09$ & 0.001 \\
$\mathrm{pH}(6-8 \mathrm{~h})$ & $7.30 \pm 0.04$ & $7.21 \pm 0.06$ & 0.002 \\
Glasgow scale $(0 \mathrm{~h})$ & $15.00 \pm 0.00$ & $13.9 \pm 1.13$ & 0.015 \\
Glasgow scale $(6-8 \mathrm{~h})$ & $15.00 \pm 0.00$ & $14.55 \pm 0.82$ & 0.247 \\
& $14 / 16$ good & $8 / 22$ good & \\
General condition & $2 / 16$ moderate & $10 / 22$ moderate & 0.077 \\
& & $4 / 22$ poor & \\
Kussmaul breathing & $16 / 16$ absent & $12 / 22$ present & 0.018 \\
& Positive $4 / 16$ & $10 / 22$ absent & \\
Anti-GAD antibodies & Negative $12 / 16$ & Positive $21 / 22$ & 0.001 \\
& Positive $6 / 16$ & Positive $18 / 22$ & \\
IA-2 antibodies & Negative $10 / 16$ & Negative $4 / 22$ & 0.074 \\
C-peptide $($ ng/mL) & $0.57 \pm 0.04$ & $0.49 \pm 0.06$ & 0.005 \\
\hline
\end{tabular}

significantly decreased after $120 \mathrm{~h}(28.32$ vs $11.9 \mathrm{pg} /$ $\mathrm{mL}, p=0.003)$. Moreover, it is shown from both Fig. 2 and Table 2 that the observed decreases regard the moderate or severe DKA subgroup, while the IL-6 levels remained almost stable in the mild DKA subgroup.

Table 3 shows the $\mathrm{pH}$ correlations with the cytokine levels and WBC in the total group of patients at diagnosis of DKA. It was observed that $\mathrm{pH}$ levels were negatively correlated with IL-6 ( $p=0.057)$, IL-8 $(p=0.023)$, IL-10 $(p=0.010), \mathrm{WBC}(p=0.001)$ and cortisol levels $(p=0.020)$.

Cytokine levels were significantly correlated with hs-CRP in the group with moderate/severe DKA, and especially at 24 hours after treatment initiation (Table 4). Thus at this time-point of DKA management, hs-CRP was significantly correlated with IL-1 $\beta$, IL-6 and IL-8 in the group with moderate/severe DKA. Moreover hsCRP was significantly correlated with IL-6 at presentation $(\mathrm{r}=0.659, p=0.028)$, and with IL-10 at $120 \mathrm{~h}$ after treatment initiation $(\mathrm{r}=0.660, p=0.027)$.

The IL-10 (0-6h) difference was correlated with serum osmolality levels only in the group with moderate/severe DKA $(p=0.051)$, but not in the group with mild DKA $(p=0.548)$ and in the total group of patients $(p=0.783)$ (Table 5).

\section{Discussion}

The present study provides evidence on the cytokine levels fluctuation before and over the course of the DKA correction, and also according to the severity of DKA. To our knowledge there are very limited studies on the above topic [6]. A novelty of our study is the recording of the cytokine levels changes over time in severe DKA.

Cytokine levels have been reported to differ during the metabolic crisis of DKA at T1DM diagnosis and in patients with a longer (>1year) diabetes duration [9]. Thus elevated plasma IL-6 and TNF- $\alpha$ levels have been reported in newly diagnosed patients with [6] or without DKA [9], in comparison with those with longer standing diabetes, suggesting a possible activation of systemic inflammatory process during early phases of T1DM [9]. Moreover, in the same group of patients, IL-8 levels did not significantly change throughout the various stages of severe DKA [9], which was also observed in our study. However in patients with a long-standing diabetes without DKA, among all cytokines, only the IL-8 levels were found to be significantly increased [9]. IL-8 has been implicated in the development of diabetic macroangiopathy and pathogenesis of 
Table 2 Cytokine and white blood cell count levels at different time points in children presenting with DKA: RepeatedMeasures ANOVA results

\begin{tabular}{|c|c|c|c|c|c|}
\hline & $\begin{array}{l}\text { Moderate / Severe DKA } \\
\quad(\mathrm{pH} \leq 7.2)(\mathrm{N}=22)\end{array}$ & $\begin{array}{c}\text { Mild DKA } \\
(\mathrm{pH}>7.2)(\mathrm{N}=16)\end{array}$ & $p$-value & Overall & $p$-value \\
\hline \multicolumn{6}{|l|}{$\mathrm{WBC}\left(/ \mathrm{mm}^{3}\right)$} \\
\hline Baseline (0h) & $19957.1(14873.2,25041.0)$ & $10520.0(4504.7,16535.4)$ & 0.010 & $15238.6(11300.6,19176.6)$ & 0.001 \\
\hline $24 \mathrm{~h}$ & $11085.7(8493.6,13677.8)$ & $10220.0(7153.0,13287.0)$ & & $10652.9(8645.0,12660.7)$ & \\
\hline $120 \mathrm{~h}$ & $6785.7(4501.0,9070.4)$ & $8180.0(5476.7,10883.2)$ & & $7482.9(5713.2,9252.5)$ & \\
\hline \multicolumn{6}{|l|}{$\operatorname{ANC}\left(/ \mathrm{mm}^{3}\right)$} \\
\hline Baseline (0h) & $14791.9(10506.8,19077.0)$ & $4255.8(0.0,9924.5)$ & 0.012 & $9523.9(5970.9,13076.9)$ & 0.003 \\
\hline $24 \mathrm{~h}$ & $6883.9(4478.2,9289.3)$ & $4646.5(1464.3,7828.8)$ & & $5765.2(3770.6,7759.7)$ & \\
\hline $120 \mathrm{~h}$ & $3220.5(1804.4,4636.6)$ & $2715.1(841.8,4588.4)$ & & $2967.8(1793.7,4142.0)$ & \\
\hline \multicolumn{6}{|l|}{$\mathrm{IL}-1 \beta(\mathrm{pg} / \mathrm{mL})$} \\
\hline Baseline (0h) & $0.95(0.08,1.82)$ & $1.280(0.26,2.30)$ & 0.707 & $1.12(0.45,1.79)$ & 0.086 \\
\hline $6-8 \mathrm{~h}$ & $0.90(0.00,1.83)$ & $1.07(0.00,2.16)$ & & $0.98(0.26,1.70)$ & \\
\hline $24 \mathrm{~h}$ & $0.89(0.00,1.80)$ & $1.04(0.00,2.10)$ & & $0.97(0.27,1.66)$ & \\
\hline $120 \mathrm{~h}$ & $0.70(0.05,1.36)$ & $0.92(0.15,1.69)$ & & $0.81(0.31,1.32)$ & \\
\hline \multicolumn{6}{|l|}{ IL-2 (pg/mL) } \\
\hline Baseline (0h) & $3.05(0.00,11.72)$ & $11.61(1.45,21.76)$ & 0.272 & $7.33(0.66,14.00)$ & 0.184 \\
\hline $6-8 \mathrm{~h}$ & $2.65(0.00,8.21)$ & $8.36(1.85,14.88)$ & & $5.51(1.23,9.79)$ & \\
\hline $24 \mathrm{~h}$ & $2.08(0.00,11.11)$ & $11.31(0.73,21.89)$ & & $6.70(0.00,13.65)$ & \\
\hline $120 \mathrm{~h}$ & $1.91(0.00,8.27)$ & $8.85(1.40,16.30)$ & & $5.38(0.48,10.28)$ & \\
\hline \multicolumn{6}{|l|}{ IL-6 (pg/mL) } \\
\hline Baseline (0h) & $28.32(13.36,43.27)$ & $11.36(0.00,30.10)$ & 0.106 & $19.84(7.85,31.82)$ & 0.087 \\
\hline $6-8 \mathrm{~h}$ & $27.27(15.58,38.97)$ & $13.59(0.00,28.26)$ & & $20.43(11.06,29.81)$ & \\
\hline $24 \mathrm{~h}$ & $23.43(14.66,32.21)$ & $11.17(0.16,22.17)$ & & $17.30(10.26,24.34)$ & \\
\hline $120 \mathrm{~h}$ & $11.90(3.75,20.05)$ & $11.88(1.66,22.10)$ & & $11.89(5.34,18.43)$ & \\
\hline \multicolumn{6}{|l|}{ IL-8 (pg/mL) } \\
\hline Baseline (0h) & $18.58(10.72,26.44)$ & $10.16(0.94,19.37)$ & 0.257 & $14.37(8.31,20.42)$ & 0.059 \\
\hline $6-8 \mathrm{~h}$ & $16.15(10.25,22.06)$ & $11.53(4.60,18.46)$ & & $13.84(9.29,18.39)$ & \\
\hline $24 \mathrm{~h}$ & $12.25(8.39,16.11)$ & $10.03(5.51,14.56)$ & & $11.14(8.17,14.12)$ & \\
\hline $120 \mathrm{~h}$ & $9.33(5.63,13.03)$ & $8.39(4.05,12.73)$ & & $8.86(6.01,11.71)$ & \\
\hline \multicolumn{6}{|l|}{$\mathrm{TNF}-\alpha(\mathrm{pg} / \mathrm{mL})$} \\
\hline Baseline (0h) & $3.85(2.80,4.91)$ & $3.17(1.94,4.41)$ & 0.410 & $3.51(2.70,4.33)$ & 0.089 \\
\hline $6-8 \mathrm{~h}$ & $2.97(2.23,3.71)$ & $2.62(1.75,3.48)$ & & $2.79(2.22,3.36)$ & \\
\hline $24 \mathrm{~h}$ & $3.01(2.02,4.00)$ & $2.85(1.69,4.01)$ & & $2.93(2.17,3.69)$ & \\
\hline $120 \mathrm{~h}$ & $3.03(2.20,3.85)$ & $3.26(2.30,4.23)$ & & $3.15(2.51,3.78)$ & \\
\hline \multicolumn{6}{|l|}{ IL-10 (pg/mL) } \\
\hline Baseline (0h) & $91.76(49.12,134.40)$ & $12.40(0.00,62.40)$ & 0.034 & $52.08(19.22,84.93)$ & 0.031 \\
\hline $6-8 \mathrm{~h}$ & $18.08(8.42,27.74)$ & $13.70(2.37,25.03)$ & & $15.89(8.45,23.33)$ & \\
\hline $24 \mathrm{~h}$ & $14.42(3.98,24.85)$ & $10.36(0.00,22.59)$ & & $12.39(4.34,20.43)$ & \\
\hline $120 \mathrm{~h}$ & $18.04(3.22,32.85)$ & $11.80(0.00,29.17)$ & & $14.92(3.50,26.33)$ & \\
\hline \multicolumn{6}{|l|}{ Cortisol ( $\mu \mathrm{g} / \mathrm{dL})$} \\
\hline Baseline (0h) & $55.89(36.54,75.23)$ & $33.92(13.40,54.44)$ & 0.210 & $44.90(30.80,59.01)$ & 0.099 \\
\hline $120 \mathrm{~h}$ & $26.33(4.42,48.24)$ & $29.63(6.39,52.87)$ & & $27.98(12.01,43.95)$ & \\
\hline \multicolumn{6}{|l|}{$\mathrm{GH}(\mathrm{pg} / \mathrm{mL})$} \\
\hline Baseline (0h) & $25.41(5.85,44.98)$ & $17.05(0.00,37.80)$ & 0.429 & $21.23(6.97,35.49)$ & 0.098 \\
\hline $120 \mathrm{~h}$ & $21.19(0.00,48.05)$ & $28.98(0.49,57.46)$ & & $25.09(5.51,44.66)$ & \\
\hline
\end{tabular}




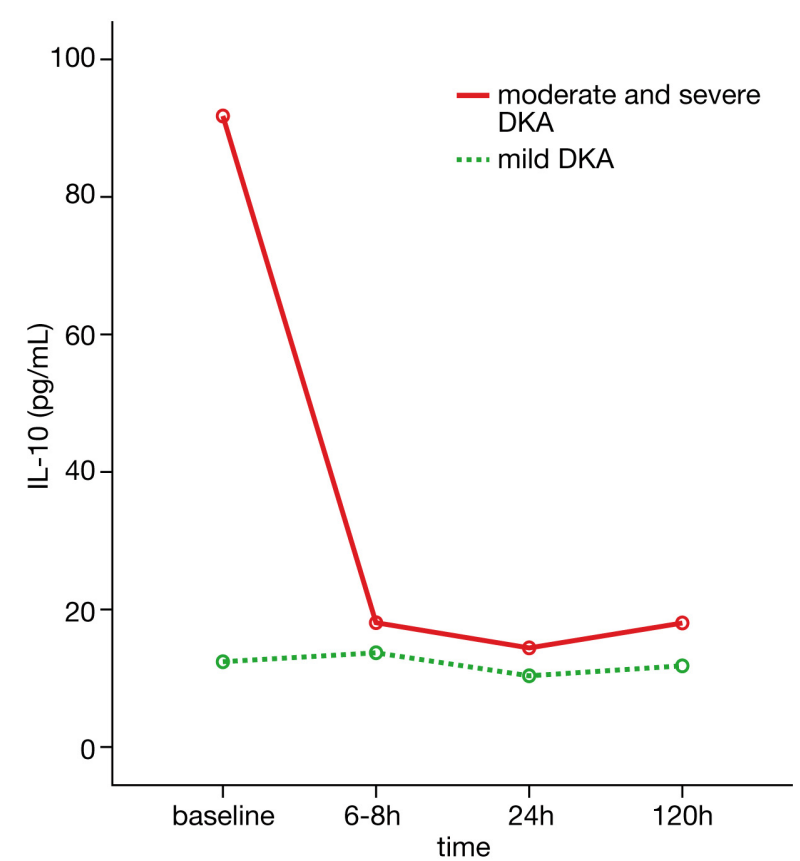

Fig. 1 Estimated marginal mean IL-10 levels at different time points and according to the degree of severity of DKA

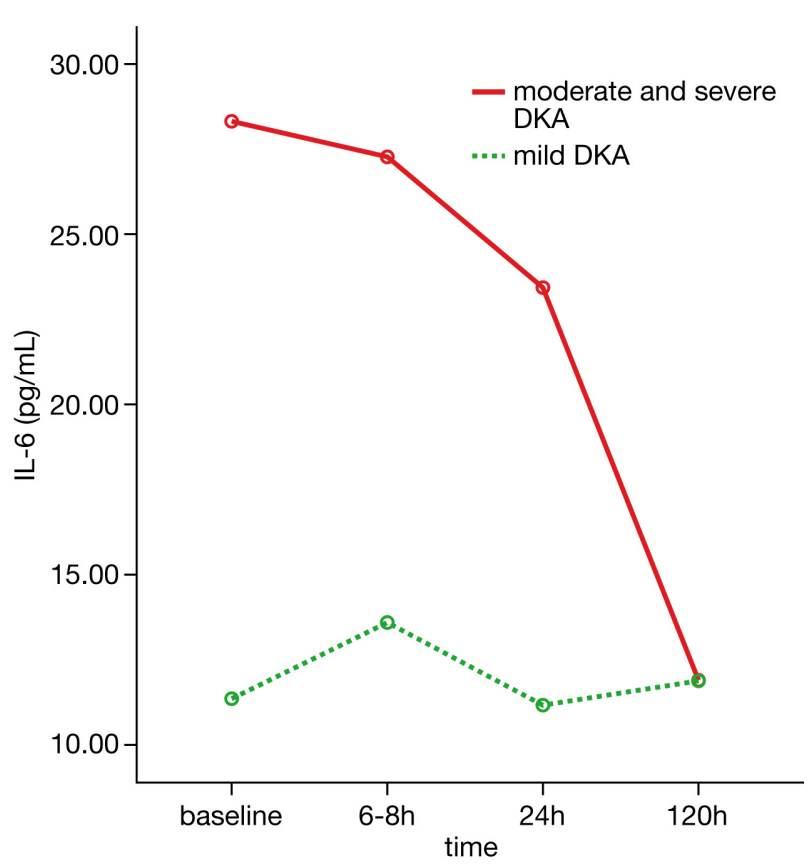

Fig. 2 Estimated marginal mean IL-6 levels at different time points and according to the degree of severity of DKA

atherosclerosis [30].

In the newly diagnosed children with T1DM and DKA of the present study, increased WBC, ANC and increased levels of IL-6 and IL-10 cytokines were observed during the first hours of DKA management, which were increased in parallel with DKA severity and they subsequently returned to normal within $120 \mathrm{~h}$ after insulin therapy and normalization of $\mathrm{pH}$ and blood glucose levels. Moreover in the group with moderate/severe DKA, hs-CRP levels were correlated with IL-6, as well as with IL-1 $\beta$ and IL-8 levels during the first 24 hours after treatment initiation, showing the degree of inflammation. Thus our study confirms the well-known phenomenon of leukocytosis in hyperglycaemic crises, without obvious infection and it also suggests a possible anti-inflammatory effect of insulin $[31,32]$. An explanation of the above is that during the hyperglycaemic crisis of DKA, stimulation of the sympathetic nervous system secondary to hyperglycaemia is observed, which results in leukocytosis and elevation of TNF- $\alpha$ and IL-6 [13]. The latter cytokines together with IL-1 $\beta$ regulate the production of acute phase proteins [33].

Moreover in our study the degree of severity of acidosis was associated with cytokine levels, WBC and cortisol levels. It has been previously reported that

\begin{tabular}{lcc}
\multicolumn{2}{c}{ serum osmolality } & \\
\hline & Spearman's rho & $p$-value \\
\hline All patients & 0.068 & 0.783 \\
Moderate/ Severe DKA & 0.600 & 0.051 \\
Mild DKA & -0.252 & 0.548 \\
\hline
\end{tabular}


in patients with DKA occurs in vivo activation of T-lymphocytes, which led to the hypothesis that hyperglycaemia and/or ketosis results in the increased production of reactive oxygen species (ROS), leading to increased levels of cytokines and emergence of growth factor receptors [34]. Actually, the anti-inflammatory role of insulin has been attributed to the fact that it influences T-lymphocyte differentiation, promoting a shift toward a Th2-type response, which leads to a diminution of cellular immune responses and a stimulation of antibody-mediated responses [35].

Significant elevation of of GH and cortisol levels was also observed during the hyperglycaemic crisis of DKA, which returned to normal after 120 hours. Similar findings have been reported by Stenz et al. [16], who observed an increase in proinflammatory cytokines, $\mathrm{GH}$, cortisol and FFAs during ketotic and non-ketotic hyperglycaemia in lean and obese patients, which returned to normal 24hours after intravenous insulin therapy.

In the present study it was noticed that during severe DKA IL-10 had the highest levels, which were significantly reduced after the first 6-8hours. Similarly Hoffman et al. [6] reported similar variations in IL-10, without however associating it to the severity of DKA. IL-10 has been shown to inhibit cytokine synthesis by human monocytes, therefore having strong downregulatory effects on the secretion of proinflammatory cytokines, which are involved in acute and chronic inflammatory processes [36]. Moreover using IL-10 i.v. as a therapeutic agent inhibits the release of TNF- $\alpha$, IL- 6 ,
IL-8, and IL-1RA and granulocyte accumulation in the lungs in healthy human volunteers [37].

Another important finding of our study was the IL-6 levels elevation during severe DKA and its reduction 120hours after treatment initiation. Similar findings have been reported by Hoffman et al. [6], without however following the IL-6 levels at different timepoints of DKA management. Furthermore, in non-severe DKA, IL-6 levels showed an increase at 6th hour after the treatment initiation. This observation has also been previously reported [6] and is suggestive of a possible role of IL-6 as a risk factor in sustaining the metabolic crisis.

Our data support the hypothesis that at the critical time-period where acute complications of DKA have been reported (6th -24th hour), the levels of IL-10 are prematurely decreased, while the levels of IL-6 remain high. Moreover, the difference between the levels of pro-inflammatory and anti-inflammatory cytokines is greater in the group with severe DKA, where acute complications are more prevalent. Thus it is suggested that the persistence of increased IL-6 levels for the critical period of 24 hours and the premature reduction of the anti-inflammatory IL-10 levels at 6 hours after treatment initiation could be associated with the development of clinical brain or pulmonary edema in children with severe DKA. Nevertheless, further clinical studies are necessary to determine if these cytokine responses are related to the pathogenesis of acute brain or pulmonary edema in children with DKA.

\section{References}

1. Levitsky L, Ekwo E, Goselink C, Solomon I, et al. (1991) Death from diabetes (DM) in hospitalized children (1970-1988). Pediatr Res 29: A195.

2. Hoffman WH, Steinhart CM, El Gammal T, Steele S, Cuadrado AR, Morse PK (1988) Cranial computed tomography in children and adolescents with diabetic ketoacidosis. Am J Neuroradiol 9: 733-739.

3. Durr JA, Hoffman WH, Sklar AH, El Gammal T, Steinhart CM (1992) Correlates of brain edema in uncontrolled insulin-dependent diabetes. Diabetes 41: 627-632.

4. Hoffman WH, Locksmith JP, Burton EM, Hobbs E, Passmore GG, Pearson-Shaver AL (1998) Interstitial pulmonary edema in children and adolescents with diabetic ketoacidosis. J Diabetes Complications 12: 314320.

5. Glaser N (2006) New Perspectives on the pathogenesis of cerebral edema complicating diabetic ketoacidosis in children. Pediatr Endocrinol Rev 3(4): 379-386.

6. Hoffman WH, Burek CL, Waller JL, Fisher LE, Khichi M, Mellick LB (2003) Cytokine response to diabetic ketoacidosis and its treatment. Clin Immunol 108: 175181.

7. Slifka MK, Whitton JL (2000) Clinical implications of dysregulated cytokine production. J Mol Med 78: 74-80.

8. Yeh FL, Lin WL, Shen HD (2000) Changes in circulating levels of anti-inflammatory cytokine interleukin 10 in burned patients. Burns 26: 454-459.

9. Erbagci AB, Tarakcioglu M, Coskun Y, Sivasli E, Sibel Namiduru E (2001) Mediators of inflammation in children with type I diabetes mellitus: cytokines in type I diabetic children. Clin Biochem 34(8):645-650.

10. Wedrychowicz A, Dziatkowiak H, Sztefko K, 
Wedrychowicz A (2004) Interleukin-6 (IL-6) and IGFIGFBP system in children and adolescents with type 1 diabetes mellitus. Exp Clin Endocrinol Diabetes 112(8): 435-439.

11. Wasmuth HE, Kunz D, Graf J, Stanzel S, Purucker EA, Koch A et al. (2004) Hyperglycaemia at admission to the intensive care unit is associated with elevated serum concentrations of interleukin- 6 and reduced ex vivo secretion of tumor necrosis factor-a. Crit Care Med 32(5): 1109-1114.

12. Esposito K, Nappo F, Marfella R, Giugliano G, Giugliano F, Ciotola M et al. (2002) Inflammatory cytokine concentrations are acutely increased by hyperglycaemia in humans: role of oxidative stress. Circulation 106: 2067 2072.

13. Goebel MU, Mills PJ, Irwin MR, Ziegler MG (2000) Interleukin-6 and tumor necrosis factor-a production after acute psychological stress, exercise and infused isopraterenal: differential effects and pathway. Psychosom Med 62: 591-598.

14. Pickup JC, Chusney GD, Thomas SM, Burt D (2000) Plasma interleukin-6, tumour necrosis factor alpha and blood cytokine production in type 2 diabetes. Life Sci 67: 291-300.

15. Jain SK, Kannan K, Lim G, Matthews-Greer J, McVie R, Bocchini JA (2003) Elevated blood interleukin-6 levels in hyperketonemic type 1 diabetic patients and secretion by acetoacetate-treated cultured U937 monocytes. Diabetes Care 26: 2139-2143.

16. Stentz FB, Umpierrez GE, Cuervo R, Kitabchi AE (2004) Proinflammatory cytokines, markers of cardiovascular risks, oxidative stress and lipid peroxidation in patients with hyperglycaemic crisis. Diabetes 53: 20792086.

17. Cucullo L, Marchi N, Marroni M, Fazio V, Namura S, Janigro D (2003) Blood-brain barrier damage includes release of alpha2-macroglobulin. Mol Cell Proteomics 2(4): 234-241.

18. Roch A, Castanier M, Mardelle V, Trousse D, Marin V, Avaro JP et al. (2008) Effect of hypertonic saline pretreatment on ischemia-reperfusion lung injury in pig. $J$ Heart Lung Transplant 27(9): 1023-1030.

19. Inoue K, Takano H, Sakurai M, Oda T, Tamura H, Yanagisawa R, Shimada A, Yoshikawa T (2006) Pulmonary exposure to diesel exhaust particles enhances coagulatory disturbance with endothelial damage and systemic inflammation related to lung inflammation. Exp Biol Med (Maywood) 231(10): 1626-1632.

20. Breithaupt-Faloppa AC, Vitoretti LB, Coelho FR, dos Santos Franco AL, Domingos HV, Sudo-Hayashi LS et al. (2009) Nitric oxide mediates lung vascular permeability and lymph-borne IL-6 after an intestinal ischemic insult. Shock 32(1): 55-61.

21. Sedgwick JB, Menon I, Gern JE, Busse WW (2002) Effects of inflammatory cytokines on the permeability of human lung microvascular endothelial cell monolayers and differential eosinophil transmigration. J Allergy Clin Immunol 110: 752-756.

22. Singh U, Devaraj S, Dasu MR, Ciobanu D, Reusch J, Jialal I (2006) C-reactive protein decreases interleukin-10 secretion in activated human monocyte-derived macrophages via inhibition of cyclic AMP production. Arterioscler Thromb Vasc Biol 26: 2469-2475.

23. Oshima T, Laroux FS, Coe LL, Morise Z, Kawachi S, Bauer P et al. (2001) Interferon-gamma and interleukin-10 reciprocally regulate endothelial junction integrity and barrier function. Microvasc Res 61(1): 130143.

24. Matsumoto K (1997) Interleukin 10 inhibits vascular permeability factor release by peripheral blood mononuclear cells in patients with lipoid nephrosis. Nephron 75(2): 154-159.

25. Matsumoto K, Ohi H, Kanmatsuse K (1997) Interleukin 10 and interleukin 13 synergize to inhibit vascular permeability factor release by peripheral blood mononuclear cells from patients with lipoid nephrosis. Nephron 77(2): 212-218.

26. Mao M, Wang SN, Lv XJ, Wang Y, Xu JC (2010) Intravenous delivery of bone marrow-derived endothelial progenitor cells improves survival and attenuates lipopolysaccharide-induced lung injury in rats. Shock 34(2): 196-204.

27. Expert Committee on the Diagnosis and Classification of Diabetes Mellitus (2003) Follow-up report on the diagnosis of diabetes mellitus. Diabetes Care 26: 31603167.

28. ISPAD Consensus Guidelines 2000 for the management of Type 1 Diabetes Mellitus in children and adolescents. Ed.PGF Swift.Publ.Medforum, Zeist, Netherlands. p.63-64.

29. Klein M, Sathasivam A, Novoa Y, Rapaport R (2009) Recent consensus statements in pediatric endocrinology: a selective review. Endocrinol Metab Clin North Am 38(4): 811-825.

30. Bruun JM, Pederson SB, Richelsen B (2000) Interleukin-8 production in human adipose tissue. Inhibitory effect of anti-diabetic compounds, the thiazollidinedione ciglitazone and the biguanide metformin. Horm Metab Res 32: 537-541.

31. Hansen TK, Thiel S, Wouters PJ, Chrstiansen JS, Van den Berghe G (2003) Intensive insulin therapy exerts anti-inflammatory effects in critically ill patients and counteracts the adverse effect of low mannose-binding lectin levels. J Clin Endocrinol Metab 88: 1082-1088.

32. Dandona P, Aljada A, Mohanty P (2002) The anti-inflammatory and potential antiatherogenic effect of insulin: a new paradigm. Diabetologia 45: 924-930.

33. Suffredini AF, Fiantazzi G, Badolto R, Oppenheimer J, O’Grady N (1999) New insights into the biology of acute phase response. J Clin Immunol 19: 203-214. 
34. Kitabchi AE, Stentz FB, Umpierrez GE (2004) Diabetic ketoacidosis induces in vivo activation of T-lymphocytes. Biochem Biophys Res Commun 315(2): 404-407.

35. Viardot A, Grey ST, Mackay F, Chishom D (2007) Potential antiiflammatory role of insulin via the preferential polarization of effector T cells toward a T Helper 2 Phenotype. Endocrinology 148 (1): 346-353.

36. Wall Malefy R, Abrams J, Bennett CG, de Vris JE (1991) Interleukin 10 (IL-10) inhibits cytokine syn- thesis by human monocytes: an autoregulatory role of IL-10 produced by monocytes. J Exp Med 174: 12091220.

37. Pajkrt D, Camoglio L, Tiel-van Buul MC, de Bruin K, Cutler DL, Affrime MB et al. (1997) Attenuation of proinflammatory response by recombinant human IL-10 in human endotoxemia: effect of timing of recombinant human IL-10 administration. J Immunol 158(8): 39713977. 